Check for updates

The BMJ

Cite this as: BMJ2020;370:m3526 http://dx.doi.org/10.1136/bmj.m3526 Published: 09 September 2020

\section{Covid-19: London hospital where 70 staff had to self-isolate must improve infection control}

Clare Dyer

A London hospital hit by a covid-19 outbreak that required 70 staff to self-isolate has been ordered to take stringent measures to control infection.

Hillingdon Hospital NHS Foundation Trust, which is in Boris Johnson's constituency, declared a covid-19 outbreak in July and revealed that 70 staff members, some of whom had tested positive, were self-isolating. Ambulances were forced to divert patients to other emergency departments.

An investigation later found that a nurse who had covid-19 unwittingly infected 16 others during a training session on 30 June, described by one doctor as a "super spreading event."

The Care Quality Commission (CQC), which carried out an unannounced inspection on 4-5 August, has used its urgent enforcement powers to place conditions on the trust's registration to protect patients and staff.

The trust's chief executive Sarah Tedford resigned on 14 August, just days after the CQC inspection, citing "family reasons." She had earlier blamed staff for not wearing masks and not socially distancing.

Nigel Acheson, the CQC's deputy chief inspector of hospitals, said, "We found a number of concerns relating to infection control and this is why we have taken action to ensure the safety of patients, staff and visitors.

"We have imposed urgent conditions upon the trust's registration and expect the trust to focus on making the required improvements as a matter of priority. We will return to inspect and ensure that action has been taken and that improvements have been made and are being sustained."

The trust has been told it must ensure that staff and patients observe social distancing, must place personal protective equipment (PPE) in easily accessible places, and must make sure that staff wear PPE before going into high risk areas.

The trust must also provide the CQC with details of any system put in place to ensure that staff are tested for covid-19 and are fit to work. The CQC must see a copy of test results that have been repeated and details of any action put in place if staff fail any retest.

Risk assessments must be carried out throughout the hospital including the wards, the education centre, the lecture theatre and syndicate rooms, corridors, and main entrance to the hospital. A copy of the risk assessments must be provided to the CQC, and the trust must set up an effective system for oversight over education centre bookings.

The trust must also provide the CQC with a copy of its written infection prevention and control action plan for the hospital, covering all areas, including dates for completion of each action, and give a weekly progress report to the CQC.

The trust said in a statement, "The safety and wellbeing of our patients and our staff must be at the heart of everything we do and we are making urgent improvements to ensure this, particularly in infection prevention and control.

"We have made physical changes to our building to support better social distancing and we have reviewed our procedures to make sure they are robust. We are working with national organisations to receive additional support and are regularly updating them on our progress.” 